\title{
Follicle-Stimulating Hormone (FSH) and Luteinizing Hormone (LH) in the Urine of Prepubertal Children*
}

\author{
Arleen B. Rifkind, Howard E. Kulin, and Griff T. Ross \\ (From the Endocrinology Section, National Institute of Child Health and Human Development, \\ and the Endocrinology Branch, National Cancer Institute, National Institutes of Health, \\ Bethesda, Maryland)
}

\begin{abstract}
Follicle-stimulating hormone (FSH) and luteinizing hormone (LH) have been measured by specific bioassays in pooled urine samples from prepubertal children, aged 2-6 yr, and from male adults. For children the mean urinary excretion of FSH was $2.2 \mathrm{U}$ 2nd International Reference Preparation (2nd IRP) per liter and the mean urinary excretion of LH was $0.44 \mathrm{U}$ 2nd IRP per liter. For adults the mean FSH excretion was $5.6 \mathrm{U}$ 2nd IRP per liter and the mean LH excretion was $4.7 \mathrm{U}$ 2nd IRP per liter. Our data show a 2.5-fold increase of $\mathrm{FSH}$, a 10.7-fold increase of $\mathrm{LH}$, and a consequent decrease in the FSH : LH ratio from 5 to 1 between childhood and adulthood. FSH and LH in urine from three patients with gonadal abnormalities have also been studied. The results from normal children, adults, and abnormal patients form a spectrum and reveal that sexual maturity is accompanied by a marked increase in the excretion of $\mathrm{LH}$ with relatively smaller increases in FSH.
\end{abstract}

\section{Introduction}

Several laboratories have reported the detection of gonadotropins in the urine of prepubertal children by bioassay (1-3). Those studies, however, report measurement of total gonadotropins, and very little information is available on the differential excretion of follicle-stimulating hormone $(\mathrm{FSH})$ and luteinizing hormone (LH) in children. While Fitschen and Clayton (2) measured $\mathrm{LH}$ in a single pool of urine from six prepubertal boys under $6 \mathrm{yr}$, there have been no reported measurements of FSH in the urine of prepubertal children.

The present study was undertaken to delineate the pattern of gonadotropin excretion in prepubertal children. We have measured FSH and $\mathrm{LH}$ by means of specific bioassays in pooled urine samples from normal prepubertal children, aged

* Received for publication 5 June 1967 and in revised form 31 July 1967.

Address requests for reprints to Dr. Arleen Rifkind, Endocrinology section, National Institute of Child Health and Human Development, Bethesda, Md. 20014.
2-6 yr, and from adult males. The data show that an increase of FSH and $\mathrm{LH}$ and a decrease in the $\mathrm{FSH} / \mathrm{LH}$ ratio are associated with sexual maturity.

\section{Sources of urine}

\section{Methods}

Children's urine was obtained from local private nursery schools. The children were not examined by the investigators but had had physical examinations during the school year and were considered healthy.

Nursery school A was attended by approximately 40 Negro children aged 3-6 yr, and nursery school B, by approximately 50 children aged $2-5 \mathrm{yr}$, most of whom were Caucasian.

Random urine specimens from the children were pooled in containers at the schools and were transported daily to the laboratory where they were stored at $4^{\circ} \mathrm{C}$ for 2 days to 2 wk until processed. Pools of urine from schools A and B were usually combined. A total of 480 liters was collected and assayed.

Laboratory personnel provided the normal adult male urine. Random specimens were pooled. A total of 426 liters was collected and assayed.

Urine was also collected and assayed from three patients with abnormalities that might be expected to be accompanied by alterations in gonadotropin excretion. 
The first patient was a $4 \frac{1}{2}$ yr old girl with moderately advanced idiopathic isosexual precocity evidenced by breast development, axillary and pubic hair, and adolescent type external genitalia, who had not yet had menarche. 11 24-hr urine specimens totalling 7.2 liters were collected from her and pooled. The second patient was a $6 \frac{1}{2}$ yr old girl with more advanced idiopathic isosexual precocity who had had menarche at 6 yr 3 months. 7 24-hr specimens totalling 9.2 liters were collected from her and pooled. The third patient was a 23 yr old female with primary amenorrhea who had a normal chromosome complement and immature ovaries. 17 24-hr specimens totalling 29 liters were collected from her and pooled.

\section{Concentration and purification}

Batches of approximately 15 liters of urine were processed separately according to Albert's kaolin-acetone method for fraction A (4). The moist precipitate was lyophilized. Fraction B (5) was then prepared, usually on amounts of precipitate equivalent to 30 liters of urine, according to the following procedure. The dry precipitate was extracted in a centrifuge tube with freshly prepared $10 \%$ ammonium acetate in $70 \%$ ethanol $(7 \mathrm{ml}$ extractant for each 3 liter equivalent of precipitate) by vigorous shaking, followed by $20 \mathrm{~min}$ of mechanical stirring at $4^{\circ} \mathrm{C}$. Centrifugation was carried out in a Sorvall $\mathrm{RC} 2 \mathrm{~B}$ centrifuge at $23,000 \mathrm{~g}$ for $15 \mathrm{~min}$, and the supernatant was decanted and saved. The residue was extracted again in the same manner, the second supernatant was added to the first, and the residue was discarded. 2 volumes of freshly prepared $10 \%$ ammonium acetate in $100 \%$ ethanol were then added to the combined supernatants. A final precipitate was allowed to form at $4^{\circ} \mathrm{C}$ for periods ranging from 2 to $14 \mathrm{hr}$. It was then spun down at $23,000 \mathrm{~g}$ for $15 \mathrm{~min}$ and saved, and the supernatant was discarded. The precipitate was dissolved in $1 \mathrm{ml}$ of distilled water for each liter equivalent of urine and frozen until used for bioassay.

\section{Bioassays}

FSH. FSH was measured by the ovarian augmentation reaction using a modification of the method of Steelman and Pohley (6). Holtzman immature female rats each weighing 40-50 g were used. Human Chorionic Gonadotropin, $150 \mathrm{U} /$ animal, was mixed and injected simultaneously with each dose of test material. Five animals were used for each test dose except when otherwise indicated. It was usually possible to discriminate between twofold dose intervals in the augmentation assay.

The 2nd International Reference Preparation for Human Menopausal Gonadotropin ${ }^{2}$ (2nd IRP) was used as

\footnotetext{
1 APL, Ayerst, N. Y.

2 Provided by Division of Biological Standards, Medical Research Council, National Institute of Medical Research, Mill Hill, London, England. Each $5 \mathrm{mg}$ ampule contains 40 international units of $\mathrm{LH}$ and 40 international units of FSH.
}

a standard in all FSH assays. Significant responses in the linear portion of the dose response curve could be assured with doses of 2 and 4 U 2nd IRP.

The pooled adult urine extract was tested at three doses equivalent to $0.33,0.67$, and 1.33 liters of urine per animal to assure at least two responses in the linear portion of the dose response curve. The children's extract was tested at one dose equivalent to 1.5 or 2.0 liters of urine per animal, except for two assays (Nos. 11 and 13) in which two doses equivalent to 1 and 2 liters of urine were used.

Doses of extract equivalent to $0.75,1.0$, and 2.0 liters of urine were used for the patient with moderate isosexual precocity, advanced isosexual precocity, and primary amenorrhea, respectively. Four animals were used to test each abnormal child's extract.

There were saline and HCG injected controls in each assay. The test materials were diluted with normal saline so that each animal would receive its total dose in a volume of $4 \mathrm{cc}$. The total dose was delivered over 4 days with $1 \mathrm{cc}$ injected the $1 \mathrm{st}$ day and $0.5 \mathrm{cc}$ injected in the morning and afternoon of the 2nd, 3rd, and 4th days. Autopsy was performed on the morning of the 5th day, and both ovaries were removed and weighed on a torsion balance.

$L H$. The ventral prostate weight assay in hypophysectomized immature male rats as described by McArthur (7) was used to measure LH. Immature SpragueDawley rats weighing 40-50 g each were delivered 1 day after hypophysectomy at which time injections were begun. Injection and autopsy schedules and total volumes of injected material were the same as in the FSH assay. Unless otherwise indicated, five animals were used for each dose. In order to discriminate between doses in the ventral prostate assay, it was usually necessary to use fourfold dose intervals.

Humegon $^{3}$ at dose levels of 0.8 and $3.2 \mathrm{U}$ with five to seven animals per dose was used as a standard in all assays. The 2nd IRP was also used as a standard in assays No. 5 and 7-10. Doses of 1.2 and $4.8 \mathrm{U}$ 2nd IRP assured consistent responses in the linear portion of the dose response curve. The data from those assays in which Humegon alone was used as a standard were converted to 2 nd IRP by means of the factor $1 \mathrm{U}$ Humegon $=1.5 \mathrm{U}$ 2nd IRP, derived from the assays in which both Humegon and 2nd IRP were used.

Doses equivalent to 0.42 and 1.67 liters of male urine per animal consistently gave differential responses and were used for all assays of male pools. In assaying children's pools, it was necessary to use amounts of extract equivalent to 2.5 or 3 liters of urine to achieve consistently significant responses. In all assays one dose was tested with five animals except for assay No. 6 in which only three animals were used.

Doses equivalent to $0.75,1.0$, and 3.0 liters of urine were used for the patients with moderate isosexual precocity, advanced isosexual precocity, and primary amenor-

${ }^{3}$ Organon, brand of human menopausal gonadotropin, Organon Inc., West Orange, N. J., Lot No. 13896/009/ 55770 . 
TABLE I

Luteinizing hormone assays of urine pools*

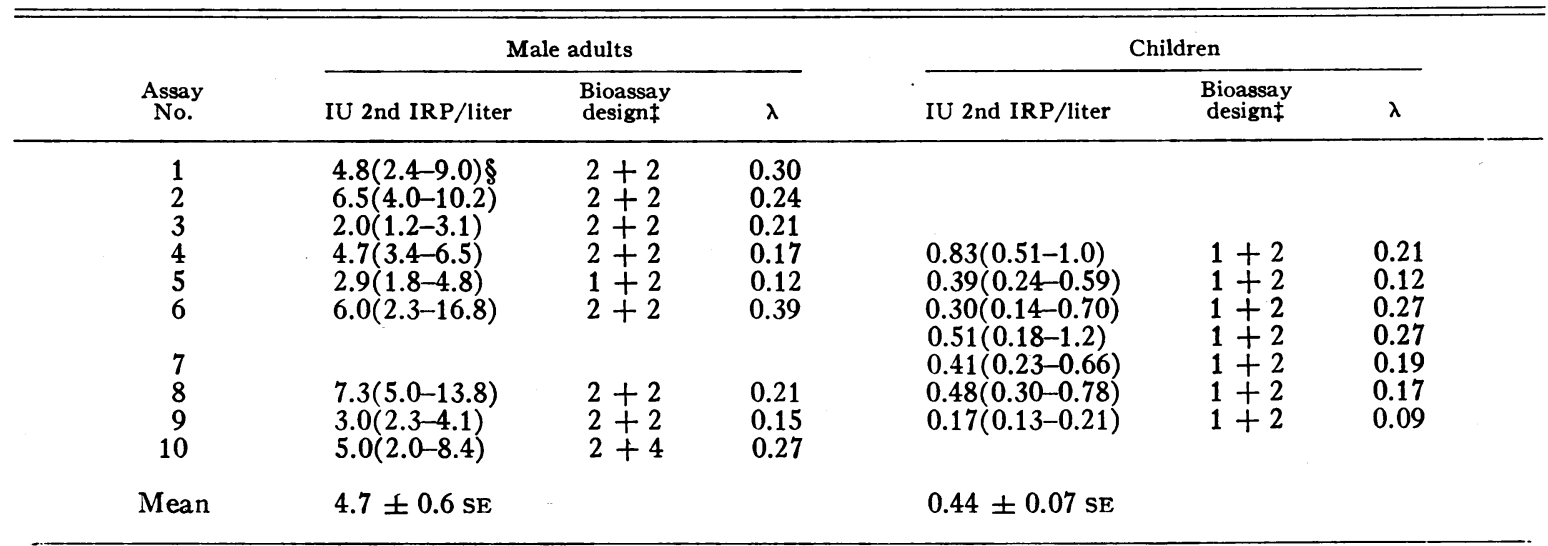

* Abbreviations: IU 2nd IRP/liter, International Units 2nd International Reference Preparation Human Menopausal Gonadotropin per liter of urine; $\lambda$, index of precision.

$\ddagger$ No. of doses of unknown plus No. of doses of standard.

$\S$ Mean potency estimate derived from bioassay of urine pool with $95 \%$ confidence limits.

rhea, respectively. Again, four animals were used for each of the extracts from the abnormal children.

\section{Statistical evaluation of bioassay data}

The data from each assay were subjected to an analysis of variance using a Fortran IV computer program designed in this laboratory (8). $F$ ratios to test for deviation from parallelism, indices of precision, and relative potencies with their $95 \%$ confidence limits, were evaluated.

\section{Results}

Table I shows the results of the $\mathrm{LH}$ assays for children and adults in terms of the 2nd IRP. All the adult pool assays had satisfactory indices of precision, and showed no significant deviation from parallelism with the standard. The mean value for $\mathrm{LH}$ in adult urine pools was $4.7 \pm 0.6$ SE U 2nd IRP per liter.

The doses of children's urine extract used always gave responses at least two standard errors above control values, except in one assay (No. 5) in which the response was one standard error above control values. It was not possible to run two discriminating doses of the children's urine because of lethal animal toxicity at higher doses. Therefore, the data for $\mathrm{LH}$ in children should be interpreted with the reservation that technical limitation did not permit any evaluation of parallelism with the standard.

Weight loss and mortality are thought to be criteria of significant toxicity in gonadotropin bio-

TABLE II

Follicle-stimulating hormone assays of urine pools*

\begin{tabular}{|c|c|c|c|c|c|c|}
\hline \multirow[b]{2}{*}{$\begin{array}{l}\text { Assay } \\
\text { No. }\end{array}$} & \multicolumn{3}{|c|}{ Male adults } & \multicolumn{3}{|c|}{ Children } \\
\hline & IU 2nd IRP/liter & $\begin{array}{l}\text { Bioassay } \\
\text { designf }\end{array}$ & $\lambda$ & IU 2nd IRP/liter & $\begin{array}{l}\text { Bioassay } \\
\text { designf }\end{array}$ & $\lambda$ \\
\hline $\begin{array}{l}11 \\
12\end{array}$ & $6.7(5.5-8.3) \S$ & $2+2$ & 0.09 & $\begin{array}{l}1.4(1.0-1.8) \\
1.1(.86-1.4) \\
2.2(1.7-2.9)\end{array}$ & $\begin{array}{l}2+2 \\
1+2 \\
1+2\end{array}$ & $\begin{array}{l}0.10 \\
0.07 \\
0.07\end{array}$ \\
\hline 13 & $3.7(3.1-4.3)$ & $2+2$ & 0.08 & $\begin{array}{l}1.8(1.6-2.2) \\
1.9(1.6-2.5)\end{array}$ & $\begin{array}{l}2+2 \\
1+2\end{array}$ & $\begin{array}{l}0.08 \\
0.09\end{array}$ \\
\hline 14 & $6.4(4.6-8.9)$ & $3+2$ & 0.17 & $\begin{array}{l}4.5(3.0-7.5) \\
2.5(1.8-3.6)\end{array}$ & $\begin{array}{l}1+2 \\
1+2\end{array}$ & $\begin{array}{l}0.18 \\
0.18\end{array}$ \\
\hline Mean & $5.6 \pm 1.0 \mathrm{sE}$ & & & $2.2 \pm 0.4 \mathrm{sE}$ & & \\
\hline
\end{tabular}

* Abbreviations as in Table I.

$\ddagger$ No. of doses of unknown plus No. of doses of standard.

$\S$ Mean potency estimate with $95 \%$ confidence limits. 
TABLE III

Differences in urinary follicle-stimulating hormone and luteinizing hormone in children and adults

\begin{tabular}{|c|c|c|c|c|c|c|}
\hline & \multicolumn{3}{|c|}{ FSH } & \multicolumn{3}{|c|}{$\mathrm{LH}$} \\
\hline & \multicolumn{2}{|c|}{ IU 2nd IRP per } & \multirow{2}{*}{$\begin{array}{l}\text { Ratio } \\
\text { adult/child }\end{array}$} & \multicolumn{2}{|c|}{ IU 2nd IRP per } & \multirow{2}{*}{$\begin{array}{l}\text { Ratio } \\
\text { adult/child }\end{array}$} \\
\hline & Liter & $\mathrm{m}^{2} / 24 \mathrm{hr} *$ & & Liter & $\mathrm{m}^{2} / 24 \mathrm{hr} \ddagger$ & \\
\hline Adult & 5.6 & 4.0 & \multirow{2}{*}{2.5} & 4.7 & 3.3 & \multirow{2}{*}{10.7} \\
\hline Child & 2.2 & 1.6 & & 0.44 & 0.31 & \\
\hline
\end{tabular}

* Adult is assumed to have average surface area of $1.8 \mathrm{~m}^{2}$ and urine volume of 1.3 liters per day.

$\ddagger$ Child, average age $4 \mathrm{yr}$, is assumed to have surface area of $0.7 \mathrm{~m}^{2}$ and urine volume of 0.5 liter per day.

assays (9). All our test rats gained weight and had mortality rates similar to the controls, thus showing no signs of major toxicity. With the high doses of children's urine, however, the test animals occasionally evidenced lethargy and roughening of fur, suggesting some toxicity. That these changes did not affect the LH potency estimates has been shown by radioimmunoassay data from our laboratory ${ }^{4}$ confirming $\mathrm{LH}$ potency estimates derived by bioassay from urine extracts of both children and adults.

Mean LH excretion for the children was $0.44 \pm$ $0.07 \mathrm{SE} U$ 2nd IRP per liter of urine. The values for children and adults differ significantly $(P<0.001)$.

Table II shows the results of the FSH assays. Three adult pools were tested with a mean value of $5.6 \pm 1.0 \mathrm{sE} U$ 2nd IRP per liter. All these assays also had. satisfactory indices of precision and showed no significant deviation from parallelism with the standard.

${ }^{4}$ Kulin, H., A. Rifkind, and G. Ross. Manuscript in preparation.
Because of insufficient material, the children's extract was tested at only one dose level in five assays. However, to assure that the children's extract gave responses that were parallel and therefore comparable to the standard, two 2-point assays, Nos. 11 and 13, were run. In both these assays, the dose response curve of the children's urine was satisfactorily parallel to the standard.

In order to test for marked variability between sources of children's urine, several urine pools from nursery schools A and B were assayed separately for FSH. Three pools from nursery school A alone gave means of $2.2,1.9$, and $4.5 \mathrm{U}$ 2nd IRP per liter. One pool from nursery school B gave a value of $2.5 \mathrm{U}$ 2nd IRP per liter. These values were sufficiently similar to suggest that there were no variations in results caused by differences in sources.

The seven pools of children's urine gave a mean value of $2.2 \pm 0.4 \mathrm{SE} U$ 2nd IRP per liter. The values for children and adults are significantly different $(P<0.005)$.

Table III contrasts excretion of FSH and LH in children and adults. The results are listed in terms of units per liter and units per meter ${ }^{2}$ per $24 \mathrm{hr}$. The estimated factor for converting excretion in terms of liters to meter ${ }^{2}$ per $24 \mathrm{hr}$ is similar in both children and adults, so that relative differences between children and adults remain the same when either units are used. Our data indicate that adult males excreted 2.5 times as much urinary $\mathrm{FSH}$ and 10.7 times as much urinary $\mathrm{LH}$ as prepubertal children, whether values are expressed per meter ${ }^{2}$ per $24 \mathrm{hr}$ or per liter of urine.

Table IV shows FSH/LH ratios in male adults,

TABLE IV

Urinary FSH/LH ratios in normal children and male adults and in selected patients

\begin{tabular}{|c|c|c|c|}
\hline \multirow[b]{2}{*}{ Urine source } & \multicolumn{2}{|c|}{ IU 2nd IRP/liter } & \multirow{2}{*}{$\underset{\mathrm{FSH} / \mathrm{LH}}{\text { Ratio }}$} \\
\hline & FSH & LH & \\
\hline $\begin{array}{l}\text { Adult, pool* } \ddagger \\
\text { Adult, pool*§ } \\
\text { Adult, means of all FSH and LH assays } \\
\text { Child, pool*\| } \\
\text { Child, means of all FSH and LH assays } \\
\text { Patient with moderate isosexual precocity* } \\
\text { Patient with advanced isosexual precocity* } \\
\text { Patient with primary amenorrhea* }\end{array}$ & 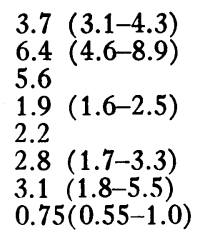 & $\begin{array}{l}3.0(2.3-4.1) \\
5.0(2.0-8.4) \\
4.7 \\
0.17(0.13-0.21) \\
0.44 \\
1.0(0.57-1.9) \\
6.0(4.2-8.1) \\
0.19(0.10-0.33)\end{array}$ & $\begin{array}{r}1.2 \\
1.2 \\
1.2 \\
11.2 \\
5.0 \\
2.8 \\
0.53 \\
4.0\end{array}$ \\
\hline
\end{tabular}

* Mean potency estimate with $95 \%$ confidence limits.

$\ddagger$ FSH and LH determinations made on aliquots of the same pool, assayed in FSH assay No. 13 and LH assay No. 9. \$ FSH and LH determinations made on aliquots of the same pool, assayed in FSH assay No. 14 and LH assay No. 10. || FSH and I.H determinations made on aliquots of the same pool, assayed in FSH assay No. 13 and LH assay No. 9. 
children, and the abnormal patients. For adults, three values are listed. The first two represent pools of urine which were divided and aliquots of the same pool assayed for FSH and LH. The third represents the $\mathrm{FSH} / \mathrm{LH}$ ratio calculated from the mean values for $\mathrm{FSH}$ and $\mathrm{LH}$ from all the assays of adult urine pools. The $\mathrm{FSH} / \mathrm{LH}$ ratio found in adults was 1.2 .

For the children, two values are listed. The first represents the ratio for one pool which was divided and aliquots assayed for FSH and $\mathrm{LH}$. The second value is the ratio of means from all the FSH and LH assays. The ratio of 11.8 from the single pool is higher than the ratio of 5.0 for the means because the single pool gave a particularly low value for $\mathrm{LH}$. Ratios between children and adults differ significantly $(P<0.005)$.

The ratio for the child with advanced isosexual precocity was 0.53 . The ratio for the child with moderate isosexual precocity was 2.8 . The ratio for the $23 \mathrm{yr}$ old female with primary amenorrhea was 4.0.

\section{Discussion}

The main problems in measuring the separate gonadotropins in children's urine by bioassay have been the difficulty in obtaining sufficient material and the toxic effects of the large amounts of urine concentrates that are needed for a significant response. The use of Albert's fraction B purification method for urine extracts has enabled us to give doses sufficient to achieve responses without obvious toxicity.

There are very few reports on $\mathrm{LH}$ excretion in children with which to compare our data. McArthur et al. (10), using kaolin-acetone extracts (fraction A) and the ventral prostate assay, were able to detect urinary LH activity in only 3 out of 12 children, aged 4-11 yr. Fitschen and Clayton (2), using fraction $\mathrm{B}$ and the ovarian ascorbic acid depletion assay for LH, found $0.89 \mu \mathrm{m}$ NIH-LH$\mathrm{S} 1 / 24 \mathrm{hr}$ in a single pool of urine from six boys under 6 yr. By converting this value to 2 nd IRP $^{5}$

\footnotetext{
5 Because the 2nd IRP has not been used as a standard in most published studies of urinary $\mathrm{FSH}$ and $\mathrm{LH}$, in order to compare our results with those of other investigators conversion factors have been used. To express NIH-FSH-S1 and NIH-LH-S1 standards in terms of the 2nd IRP, Rosemberg and Lewis' (11) factors, $1 \mathrm{mg}$ NIH-FSH-S1 = $25 \mathrm{U}$ 2nd IRP and $1 \mathrm{mg}$ NIH-LH-S1 =
}

a value of $0.45 \mathrm{U}$ 2nd IRP/24 hr is obtained. FSH has not been measured previously in the urine of children under $10 \mathrm{yr}$.

Our results for $\mathrm{FSH}$ and $\mathrm{LH}$ in adult males agree well with other published values on male urine pools $(5,12,13)$ when the reported values have been converted to 2nd IRP (11).

Urinary excretion of both FSH and $\mathrm{LH}$ appears to undergo an increase as sexual maturity is reached. However, our data suggest that whereas FSH is present in the urine in easily detectable amounts before puberty and increases only about 2.5 -fold by adulthood, $\mathrm{LH}$ is barely detectable in the urine of younger children and increases approximately 10.7 -fold in adults. Several investigators $(10,14)$, have speculated, on the basis of indirect evidence, that there would be more $\mathrm{FSH}$ than $\mathrm{LH}$ in the urine of prepubertal children. The greater increase of $\mathrm{LH}$ associated with puberty is responsible for a shift in $\mathrm{FSH} / \mathrm{LH}$ ratios from prepubertal values of about 5.0 to adult values of about 1.2.

Though information derived from a few individuals may be misleading, the data from the pathologic cases which have been studied here fit well into the observed pattern of decreasing FSH/ $\mathrm{LH}$ ratios associated with sexual maturity. Whether the $\mathrm{FSH} / \mathrm{LH}$ ratio or a specific amount of $\mathrm{FSH}$ and/or $\mathrm{LH}$ is a critical factor in the initiation of puberty cannot be answered by this study. The failure of sexual development in the $23 \mathrm{yr}$ old patient with primary amenorrhea who had both a childhood type of $\mathrm{FSH} / \mathrm{LH}$ ratio and childhood levels of FSH and LH does not help in discriminating among these possibilities. The ratio of 0.53 in the child with advanced isosexual precocity was closest to the adult ratio. The ratio of 2.8 in the patient with moderate isosexual precocity who had not had the onset of menarche was intermediate between the ratios for children and adults. The development of puberty in both these children in whom $\mathrm{LH}$, but not FSH, had increased significantly above childhood levels suggests that physiologic changes may be associated with increments in $\mathrm{LH}$ alone.

There are no data with which to compare our

$62.5 \mathrm{U}$ 2nd IRP, were used. It must be emphasized that conversion factors applicable in one laboratory cannot be used by another with any certainty of accuracy. 
FSH/LH ratios in children. However, our ratio of 1.2 in males agrees well with the results of other investigators $(5,12,13,15,16)$ who have reported $\mathrm{FSH} / \mathrm{LH}$ ratios in male urine ranging from 1.1 to 2.5. As Rosemberg and Solod (15) have pointed out, individual variability of $\mathrm{FSH} /$ LH ratios may be masked by pooled samples.

Differences in $\mathrm{FSH} / \mathrm{LH}$ ratios between men, postmenopausal women, and eunuchs are still a matter of some controversy. Whereas most investigators $(12,13,15-19)$ found that $\mathrm{FSH} / \mathrm{LH}$ ratios in urine pools from men and postmenopausal women were similar, others (20-21) report differences. Eunuchs, however, have uniformly been found to have urinary $\mathrm{FSH} / \mathrm{LH}$ ratios 2.0 to 6 times higher than either normal men or postmenopausal women $(13,16,17)$. Although prepubertal children excrete smaller amounts of gonadotropin than eunuchs they exhibit the same high FSH/ $\mathrm{LH}$ ratio.

We cannot be certain that the differences in urinary gonadotropin excretion between children and adults reported here are accurate reflections of differences in plasma levels. The resolution of this problem awaits the perfection of techniques for measurement of $\mathrm{FSH}$ and $\mathrm{LH}$ in low titer plasma.

While it is possible that the observed changes in gonadotropin excretion are causal factors in sexual development they may be mere accompaniments of that process and other factors may be crucial. Thus, consideration should be given to explanations of sexual maturation in terms of possible differences in chemical structure between gonadotropins of children and adults, or the development of circadian peaks of gonadotropin release by the pituitary, or as yet undetermined differences in gonad sensitivity between children and adults. Though significant changes in gonadotropin excretion between childhood and adulthood have been demonstrated in this study, the causes of puberty are still unknown.

\section{Acknowledgments}

We are grateful to Mrs. C. Bowden and the staff and children of Green Hill Day Nursery and Mrs. A. Trainor and the staff and children of the Bethesda Community School for their cooperation in the difficult job of collecting urine, to Mr. James Brice for his excellent technical assistance, and to Dr. John Gart for his help in the statistical evaluation.

\section{References}

1. Carletti, B., and E. Kehyayan. 1962. Caratteristiche biologiche delle gonadotropine urinarie nell'infanzia. Minerva Pediat. 14 : 786.

2. Fitschen, W., and B. E. Clayton. 1965. Urinary excretion of gonadotrophins with particular reference to children. Arch. Dis. Childhood. $40: 16$.

3. Kulin, H. E., A. Rifkind, G. T. Ross, and W. D. Odell. 1967. Total gonadotropin activity in the urine of prepubertal children. J. Clin. Endocrinol. Metab. 27 : 1123.

4. Albert, A. 1956. Human urinary gonadotropin. Recent Progr. Hormone Res. 12 : 227.

5. Albert, A., J. Kobi, J. Leiferman, and I. Derner. 1961. Purification of pituitary gonadotropin from urine of normal men. J. Clin. Endocrinol. Metab. $21: 1$.

6. Steelman, S. L., and F. M. Pohley. 1953. Assay of the follicle stimulating hormone based on the augmentation with human chorionic gonadotropin. Endocrinology. 53 : 604.

7. McArthur, J. W. 1952. The identification of pituitary interstitial cell stimulating hormone in human urine. Endocrinology. 50: 304.

8. Cooper, J. A. 1966. A New Computer Program for the Statistical Evaluation of Biologic Assay Data. Endocrinology and Metabolism Branch, National Institute of Child Health and Human Development, NIH, Bethesda, Md.

9. McArthur, J. W., A. Howard, A. Somerville, R. Perley, and C. Keyes. 1967. Relative toxicity of gonadotropic extracts prepared from postmenopausal urine by the Albert and Johnsen methods. J. Clin. Endocrinol. Metab. $27: 534$.

10. McArthur, J. W., F. M. Ingersoll, and J. Worcester. 1958. Urinary excretion of interstitial-cell stimulating hormone by normal males and females of various ages. J. Clin. Endocrinol. Metab. 18: 460.

11. Rosemberg, E., and W. B. Lewis. 1966. Comparative activities of human urinary postmenopausal gonadotropins. J. Clin. Endocrinol. Metab. 26: 786.

12. Albert, A., I. Derner, V. Stellmacher, J. Leiferman, and J. Barnum. 1961. Purification of pituitary gonadotropin from urine of postmenopausal women. J. Clin. Endocrinol. Metab. $21: 1260$.

13. Albert, A., I. Derner, J. Leiferman, V. Stellmacher, and J. Barnum. 1961. Studies on the biologic characterization of human gonadotropins. VII. Urinary gonadotropins of men, postmenopausal women and eunuchs. J. Clin. Endocrinol. Metab. $21: 839$.

14. Brown, P. S. 1958. Human urinary gonadotrophins. I. In relation to puberty. J. Endocrinol. 17: 329.

15. Rosemberg, E., and E. A. Solod. 1964. Biologic characterization of human gonadotropins obtained from the urine of men and postmenopausal women. J. Clin. Endocrinol. Metab. 24 : 644.

16. Becker, K. L., and A. Albert. 1965. Urinary excretion of follicle-stimulating and luteinizing hormones. J. Clin. Endocrinol. Metab. 25 : 962. 
17. Rosemberg, E., and I. Engel. 1962. Biologic characterization of human gonadotropins obtained from the urine of men, postmenopausal women and eunuchs. J. Clin. Endocrinol. Metab. $22: 377$.

18. Albert, A., S. Kelly, and J. Kobi. 1958. Studies on the biologic characterization of human gonadotropins. I. Human pituitary gonadotropin from urine of normal men, and postmenopausal and castrated women. J. Clin. Endocrinol. Metab. $18: 843$.

19. Mellinger, R. C., J. A. Mansour, and R. W. Smith, Jr. 1963. Bioassay characteristics of individual urinary gonadotrophin extracts. Acta Endocrinol. 42: 214.

20. Hamburger, C., and S. G. Johnsen. 1957. Studies on urinary gonadotrophins. III. Qualitative differences between urinary gonadotrophins of young males and of postmenopausal women. Acta Endocrinol. $26: 1$.

21. Blatt, W. F., M. Y. Park, M. L. Taymor, and R. Todd. 1966. Separable gonadotropin activity in the urine of normal males and postmenopausal females. J. Clin. Endocrinol. Metab. 26: 189. 